\title{
Antioxidant Activities of Satureja hortensis L. Essential Oil during the Flowering Period
}

\author{
Gülsüm YALDIZ, Mahmut ÇAMLICA \\ Department of Field Crops, Faculty of Agriculture and Natural Sciences, Abant İzzet Baysal University, 14280 Bolu, TURKEY
}

\begin{abstract}
Objective: This study was conducted to investigate the changes of total phenolic concentration and antioxidant activity of Satureja hortensis L. during the flowering stage cultivated under the ecological conditions of Rize, Turkey. Material and Methods: The plantation was established with natural cuttings of Satureja hortensis L. Cuttings were obtained at three stages (pre-flowering, full flowering, and post-flowering) and dried in an oven at $35^{\circ} \mathrm{C}$. The analysis of essential oil in the leaves and flowers of the samples was carried out using a Clevenger aparatus for three hours. The total phenolics and antioxidant activity of essential oils was evaluated by Folin-Ciocalteu and DPPH free radical scavenging assays, respectively. Results: The total phenolic content varied between $746 \pm 4$ and $1087 \pm 44 \mu \mathrm{M}$, and the highest value was obtained from the full-flowering stage. The $\mathrm{SC}_{50}$ values in the $\mathrm{DPPH}$ assay ranged from $6.65 \pm 0.38$ to $16.10 \pm 0.99 \mu \mathrm{M}$ catechin equivalent and the highest activity was observed in the full flowering stage. Among all the samples, the essential oil of the cutting taken during the full flowering period showed the highest phenolic concentration and antioxidant activity. Conclusion: Satureja hortensis L. is a good natural antioxidant source with its high phenolic concentration and antioxidant activity.
\end{abstract}

Keywords: Satureja hortensis L, antioxidant activity, essential oil, polyphenol content, harvest times

\section{INTRODUCTION}

Phenolic compounds exhibit a wide range of physiological activities, such as antioxidant, anti-allergenic, anti-artherogenic, antiinflammatory, antimicrobial, anti-thrombotic, cardioprotective, vasodilatory effects, and anti-carcinogenic. ${ }^{1-3}$ Natural antioxidants can protect the human body from free radicals and are reported to slow the progress of many chronic diseases as well as lipid oxidative rancidity in foods. ${ }^{4}$ Satureja hortensis L. (S. hortensis) belongs to the family Lamiaceae. In Turkey, it is known as "yaz zahteri, çorba kekiği" and used as a culinary herb and for medicinal purposes. S. hortensis grows on serpentine hills, spread on dry, rocky and sunny hillsides, from the lowland to the mountains. ${ }^{5}$ The essential oil of $S$. hortensis cultivated in summer has been found to be rich in $\gamma$-terpinene and carvacrol $^{6}$ and have a variety of antibacterial, antifungal, antioxidant, antispasmodic, antidiarrheal and sedative properties. $^{7-9}$ Many studies have reported that the essential oil of $S$. hortensis and their main phenolic constituents such as carvacrol and $\gamma$-terpinene show remarkable antifungal, antibacterial and antimicrobial activities. $^{10,11}$ In Turkey, dried herbs of savory are used as herbal tea and condiment in addition to being utilized in folk medicine to treat asthma, colic, bronchitis, and coughs and in food industry as flavoring, aromatic and preservative agents. The aim of this study was to evaluate the influences of total phenolic concentration and antioxidant activity of $S$. hortensis essential oil collected from savory at three different stages in an experimental field.
DOI: 10.5530/ijper.51.3s.25 Correspondence: Gülsüm YALDIZ, Department of Field Crops, Faculty of Agriculture and Natural Sciences, Abant İzzet Baysal University, 14280 Bolu, TURKEY Contact: +90 37425343 45- 2602

E-mail: yaldizgulsum@gmail. com 


\section{MATERIALS AND METHODS}

\section{Plant material and growth conditions}

The seedling used in the study was collected from the Şavşat district of Artvin province, Turkey and cultivated in May 2010 under the ecological conditions of Rize $\left(41^{\circ}-20^{\prime} \mathrm{N}, 41^{\circ}-28^{\prime} \mathrm{E}\right)$ at a research and application area belonging to Pazar Vocational School of Recep Tayyip Erdoğan University. The soil of the field area was of a sandy clay loam texture with medium acidity $(\mathrm{pH}=5.2)$, low lime content $(2.02 \%)$, medium nitrogen $(0.14 \%)$, salt $(0.56 \%)$ and phosphorus (1.86 ppm), little organic material (1.25\%) and high level of potassium (250 ppm). During the vegetation period (May-August), the experimental area had an average temperature of $19.5^{\circ} \mathrm{C}$ and humidity of $78.8 \%$, and the total precipitation $651.2 \mathrm{~mm}$. A total of 40 plants were cultivated in each plot at a planting distance of $45 \times 15 \mathrm{~cm}$. After planting of the seedlings, $12 \mathrm{~kg} / \mathrm{da}$ calcium ammonium nitrate $(26 \% \mathrm{~N})$ was applied as upper fertilizer. The study was carried out in three different harvest times as follows: pre-flowering (June 10, 2010), full flowering (July 3, 2010) and postflowering (July 30, 2010).

\section{Essential oil extraction}

Plant materials were dried in an oven at $35^{\circ} \mathrm{C}$ and the leaves were separated from the other plant parts. Essential oils from each harvest of dried leaves $(20 \mathrm{~g})$ were isolated by a Clevenger-type apparatus for $3 \mathrm{~h}$.

\section{Determination of total phenolic content and antioxidant activity}

The phenolic content in the essential oils of $S$. hortensis was spectrophotometrically determined at $700 \mathrm{~nm}$ by Folin-Ciocalteu's colorimetric method and expressed as catechin $(\mathrm{mM})$ equivalents. ${ }^{12}$ The antioxidant activity of the essential oils was measured by utilizing the diphenyl picrylhydrazil (DPPH) method and expressed as $\mathrm{SC}_{50}$ $(\mathrm{mg} / \mathrm{mL})$; i.e., the concentration necessary for $50 \%$ reduction of the DPPH. ${ }^{13}$

\section{Statistical analysis}

The data were subjected to an analysis of variance (ANOVA) using Statistical Analysis System (SAS) computer software at $\mathrm{P}<0.05$ and the means were compared with Duncan's new multiple range test (DNMRT).

\section{RESULTS AND DISCUSSION}

In this study, the total phenolic content of the essential oils ranged from $746 \pm 4$ to $1087 \pm 44 \mu \mathrm{M}$. The antioxidant activities of these essential oils during the pre-, full and post-flowering stages were recorded as $6.65 \pm 0.38,16.10 \pm 0.99$ and $6.87 \pm 0.27 \mu \mathrm{M}$ catechin equivalent, respectively (Table 1). The highest phenolic concentration and antiradical activity were obtained from the essential oil extracted from the plant during the full flowering period (Figure 1, Figure 2).

In a similar study, Alizadeh et al. ${ }^{14}$ investigated the antioxidant activity and total phenolic content of $S$. hortensis extracts using a DPPH free radical scavenging assay and the Folin-Ciocalteu method. The authors reported that the total phenolic content varied between 23.58 and $24.52(\mathrm{mg}$ gallic acid equivalent $/ \mathrm{g} \mathrm{dw})$ and the IC50 values ranged from 8.45 to $8.6 \mu \mathrm{g} / \mathrm{ml}$. Furthermore, the highest values for both phenolic content and $\mathrm{IC}_{50}$ were obtained from the $1000 \mathrm{mg} /$ plant complete fertilizer treatment. Dorman and Hiltunen ${ }^{15}$ used the same method and estimated the total extractable phenolic contents of the crude extract of savory and hexane, ethyl acetate, n-butanol and water fractions as $166 \pm 2.7$, $37.1 \pm 1.1,500 \pm 47.3,27.0 \pm 9.1$, and $67.2 \pm 25.2 \mathrm{mg}$, respectively. The researchers also evaluated the free radical scavenging activity and the components within both the $\mathrm{n}-\mathrm{BuOH}$ and $\mathrm{H}_{2} \mathrm{O}$ fractions, and found the order of $\mathrm{DPPH}$ with $\mathrm{IC}_{50}$ as $3.43 \pm 0.082$ and $2.16 \pm$ $0.040 \mathrm{mg} / \mathrm{ml}$, respectively. The antioxidant properties of thymol, carvacrol, and $\gamma$-terpinene have also been previously reported. ${ }^{16-18}$ Therefore, it is considered that the activity of essential oil is related to high contents

\begin{tabular}{ccc}
$\begin{array}{c}\text { Table 1: Total phenolic substances } \\
\text { values of Satureja hortensis } \mathbf{L} \text {. essential oils during flowering period }\end{array}$ \\
\hline Samples & Total Polyphenol $(\boldsymbol{\mu M}, \mathbf{n : 6})^{\S}$ & DPPH Activity $\left(\mathbf{S C 5 0 , \mu M , n : 6 ) ^ { \ddagger }}\right.$ \\
\hline Standart (Catechin) & - & $9.0 \pm 1,0$ \\
Pre-flowering period & $746 \pm 4 \mathrm{a}$ & $6.65 \pm 10,38$ \\
Full-flowering period & $1087 \pm 44 \mathrm{~b}$ & $16.10 \pm 0,99$ \\
Post-flowering period & $1022 \pm 24 \mathrm{~b}$ & $6.87 \pm 0,27$ \\
\hline
\end{tabular}

$\S$ : Molar concentrations of total polyphenols in catechin molecular weight equivalent.

\#: Total phenolic concentration necessary for $50 \%$ reduction DPPH.

a: Indicates a significant difference at $\mathrm{P}<0.005$

$\mathrm{b}$ : In the same column with different superscripts differ significantly at $P<0.005$ 


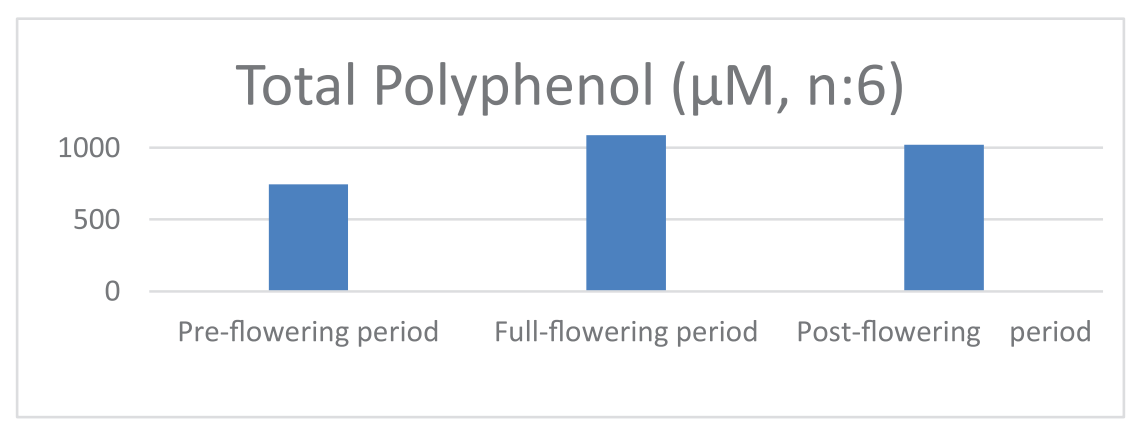

Figure 1: Total phenolics of Satureja hortensis L. essential oils during flowering period

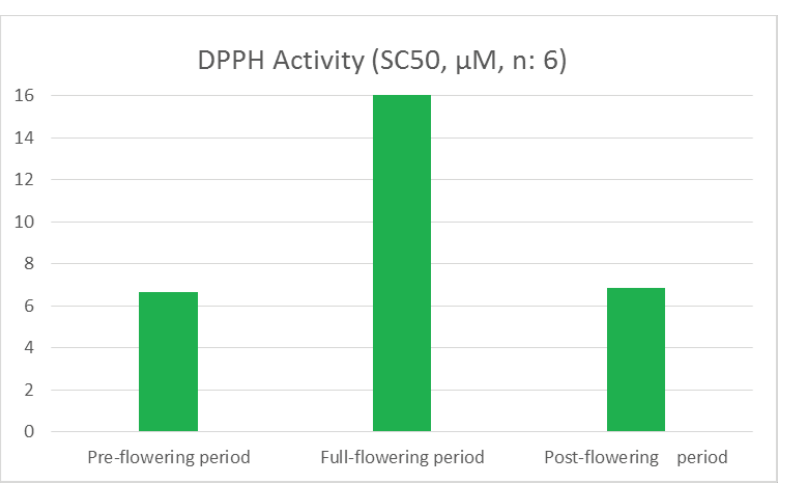

Figure 2: DPPH scavenging activity of Satureja hortensis L. essential oils during flowering period

of these components in savory oil. The presence of phenolic acids such as rosmarinic acid derivatives in S. hortensis has been demonstrated, ${ }^{19}$ and these polyphenols has been shown to possess an antioxidant activity in different test systems. ${ }^{20}$ Thus, the activity observed in the DPPH assay can be related to the presence of rosmarinic acid derivatives in the extract.

The differences between the results of the current study and those of earlier studies may be due to the use of different extracts for analyses, environmental and genetic factors, chemo-types and the nutritional status of the plants as well as other factors that may have an influence on the antioxidant activity and total phenolic content. Several studies have suggested a relationship between antioxidant activity and phenolic contents of plants. ${ }^{15,21-23}$ Similarly, in the current study, we found a positive correlation between the total phenolic content and antioxidant activity in all plant extracts.

\section{CONCLUSION}

Based on the results of this study, we determined that the antioxidant activity and phenolic content were significantly affected by harvesting times. The essential oils extracted from $S$. hortensis during the full flowering period showed the highest phenolic concentration and antioxidant activity. It is concluded that Satureja hortensis
L. is a good natural antioxidant source with its high phenolic content and antioxidant activity.

\section{ACKNOWLEDGEMENT}

None

\section{CONFLICT OF INTEREST}

None

\section{ABBREVIATIONS USED}

DPPH: 2,2-diphenylpicrylhydrazyl; DNMRT: Duncan's new multiple range test; ANOVA: Analysis of variance; SAS: Statistical Analysis System ;SC50: scavenging concentration $50 \%$.

\section{REFERENCES}

1. Jeffery EH, Keck AS. Translating knowledge generated by epidemiological and in vitro studies into dietary cancer prevention. Molecular Nutrition and Food Research. 2008;52(1):7-17.

2. Manach C, Mazur A, ScalbertA. Polyphenols and prevention of cardiovascular diseases. Curr Opin Lipidol. 2005;16(1):7-84.

3. Middleton E, Kandaswami C, Theoharides TC. The effects of Plant Flavonoids on mammalian cells: Implications for inflammation, heart disease, and cancer. Pharmacol Rev 2000;52(4): 673-751.

4. Milos M, Radonic A, Bezic N, Dunki, V. Localities and seasonal variation in the chemical composition of essential oils of Satureja montana L. and S. cuneifolia Ten. Flavour Fragrance Journal 2001;16(3):157-160.

5. Daneshvar-Royandezagh SKM, Khawar S, Ozcan, M. In vitro micropropagation of garden thyme (Thymbra spicata L. var. spicata L.) collected from Southeastern Turkey using cotyledon node, Biotechnology and Bioengineering Eq. 2009;23(3):1319-1321.

6. Go'ra J, Lis A, Lewandowski A. Chemical composition of the essential oil of cultivated summer savory (Satureja hortensis L. cv. Saturn). Journal of Essential Oil Research 1996;8(4):427-8.

7. Gulluce M, Sokmen M, Daferera D, Agar G, Ozkan H, Kartal N, et al. In vitro antibacterial, antifungal, and antioxidant activities of the essential oil and methanol extracts of herbal parts and callus cultures of Satureja hortensis L. Journal of Agricultural and Food Chemistry. 2003;51(14):3958-65.

8. Hajhashemi V, Sadraei H, Ghannadi AR, Mohseni M . Antispasmodic and antidiarrheal effect of Satureja hortensis L. essential oil. Journal of Ethnopharmacology. 2000;71(3):187-92.

9. Madsen HL, Andersen L, Christiansen L, Brockhoff P, Bertelsen G. Antioxidative activity of summer savory (Satureja hortensis L.) and rosemary 
(Rosmarinus officinalis L.) in minced, cooked pork meat. Food Research and Technology 1996;203(4):333-8.

10. Baytop T. Therapy with Medicinal Plants in Turkey, İstanbul, Publication of İstanbul University, 1984; No. 2355, Faculty of Pharmacy, No. 40.

11. Shelef LA. Antimicrobial effects of spices. Journal of Food Safety. 1984;6(1):29-44.

12. Slinkard K, Singleton VL. Total phenol analyses: Automation and comparison with manual methods. American Journal of Enology and Viticulture. 1977;28(1):49-55.

13. Cuendet $\mathrm{M}$, Hostettmann $\mathrm{P}$, Potterat $\mathrm{O}$. Iridoid Glucosides with Free Radical Scavenging Properties from Fagraea blumei, Helvetica Chimica Acta. 1997;80(4):1144-52.

14. Alizadeh A, Khoshkhui M, Javidnia K, Firuzi O, Tafazoli E, Khalighi A. Effects of fertilizer on yield, essential oil composition, total phenolic content and antioxidant activity in Satureja hortensis L. (Lamiaceae) cultivated in Iran. Journal of Medicinal Plants Research. 2010;4(1):33-40.

15. Dorman HJD, Hiltunen R. Fe(III) reductive and free radical-scavenging properties of summer savory (Satureja hortensis L.) extract and subfractions. Food Chemistry 2004;88(2):193-9.

16. Didry N, Dubreuil L, Pinkas M. Antibacterial activity of thymol, carvacrol and cinnamaldehyde alone or in combination. Pharmazie. 1993;48(4):301-4.
17. Daferera DJ, Basil N, Ziogas M, Polissiou G. The Effectiveness of plant essential oils on Botrytis cinerea, Fusarium sp. and Clavibacter michiganensis subsp. michiganensis. Crop Protection. 2003;22(1):39-44

18. Daferera DJ, Basil N, Ziogas M, Polissiou G. GC-MS analysis of essential oils from some Greek aromatic plants and their fungitoxicity on Penicillium digitatum. Journal of Agricultural Food Chemistry. 2000;48(6):2576-81.

19. Bertelsen G, Christophersen C, Nielsen PH, Madsen HL, Stadel P. Chromatographic isolation of antioxidant guided by a methyl linoleate assay. Journal of Agricultural Food Chemistry. 1995;43(5):1272-5.

20. Lu YR, Foo LY. Antioxidant activities of polyphenols from sage (Salvia officinalis). Food Chemistry. 2001;75(2):197-202.

21. Ruberto G, Batatta MT. Antioxidant activity of selected essential oil components in two lipid model systems. Food Chemistry. 2002;69(2):167-74.

22. Cai YZ, Sun M, Xing J, Luo Q, Corke H. Structure-radical scavenging activity relationships of phenolic compounds from traditional Chinese medicinal plants. Life Science. 2006;78(25):2872-88.

23. Canadanović-Brunet J, Ćetković G, Dilas S, Tumbas V, Bogdanović V, Mandić A, et al. Radical scavenging, antibacterial and antiproliferative activities of Melissa officinalis L. extracts. Journal of Medicinal Food. 2008;11(1):133-43.

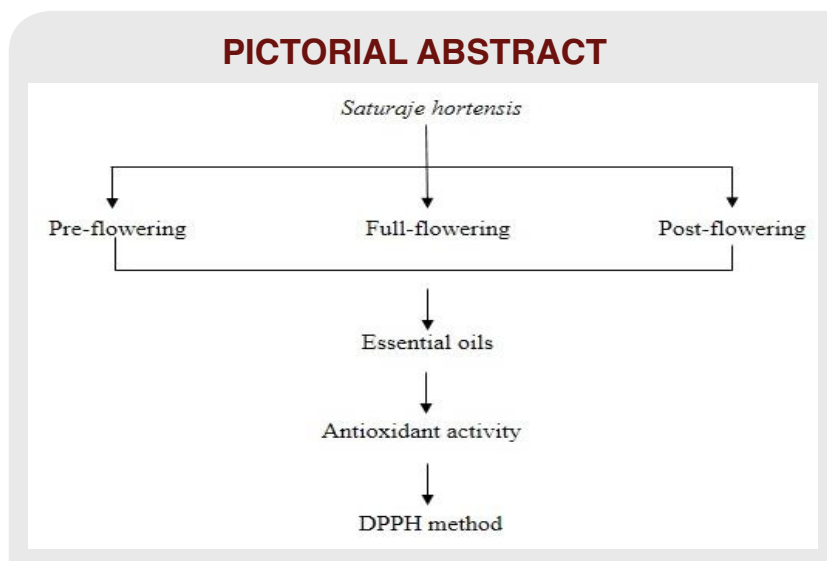

\section{SUMMARY}

- The antioxidant activity and phenolic content were significantly affected by harvesting times

- All essential oils have shown high and different DPPH scavenging activity

- The highest phenolic concentration and antioxidant activity were obtained from the essential oil extracted from the plant during the full flowering period

- There was a positive correlation between the total phenolic content and antioxidant activity in all essential oils

\section{About Authors}

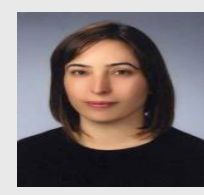

Gülsüm Yaldiz: She graduated from Faculty of Agriculture in Cukurova University and get BS degree in 2001. She obtained her Ph.D. degree in 2008 from Department of Field Crop, Cukurova University. She is positioned as Assistant Professor, Department of Field Crops, Faculty of Agriculture and Natural Sciences in Abant Izzet Baysal University. Her mainly subjects of interest are good agricultural practices, natural medicinal product, biological and chemical properties of plants.

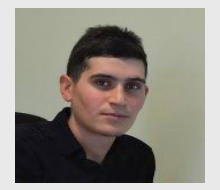

Mahmut Çamlica: Is presently working as research assistant at the Department of Medicinal and Aromatic Plants, Faculty of Agriculture and Natural Sciences in Abant Izzet Baysal University. His studies mainly focused on the natural medicinal and aromatic plant product, salinity and good agricultural practices.

Cite this article: Yaldiz G, Çamlica M. Antioxidant Activities of Satureja hortensis L. Essential Oil during the Flowering Period. Indian J of Pharmaceutical Education and Research. 2017;51(3)Suppl:S258-61. 